\title{
Void Formation in Digital Architecture Interfaces
}

\author{
Basim Hassan Almajidia , Shams Abdul Ameer Kafi a* \\ ${ }^{a}$ University of Technology / Department of Architecture, Baghdad, Iraq
}

\section{ARTICLE INFO}

Article history:

Received 03 May 2020

Received in revised form 16 June 2020

Accepted 26 June 2020

\section{Keywords:}

Void

digital formation

interfaces

digitization

\begin{abstract}
A B S T R A C T
In the last era of the digital revolution, architectural outputs with distinctive void formations appeared. The development in digital technologies, which adopts solid geometry in the formation of its interfaces. So the void became an integral part of the design at the level of three dimensions, to serves as a fourth dimension of architecture. By connecting architecture with the time, the limits of length, width, and height fade away and change from the limits of place to those of time, and this void shifts out from achieving the aesthetic needs to achieving functional and structural needs. The direct correlation of the architectural void with the process of forming the interfaces led it to be considered as a basic architectural formation unit, and in light of this, the research problem was presented as (insufficient knowledge about the importance and role of the three-dimensional architectural void and the mechanisms of its formation in the interfaces of contemporary digital architecture as a void that generates or creates the design within the needs of the designer and the receiver ). The aim of the research came to reveal the concept of architectural void at the three-dimensional level, as well as revealing strategies and mechanisms for shaping the void in the interfaces. The research adopted the descriptive and analytical research methodology in proposing theoretical knowledge extracted from previous studies of building the theoretical framework for the geometry terms which contains (strategies for forming digital void, characteristics of void in digital output, features of digital spatial structure), and applying it on contemporary architectural models with a qualitative measure that is aimed at knowing the effect of terms on the selected samples and the percentage of their effectiveness in the characteristics of the digital output, and verifying the main research hypothesis which stipulated the adoption of the strategy of forming the digital void to combine the mechanisms of digital formation that is used to create void formation to meet the needs in contemporary architecture. The results indicated that the disappearance of the boundaries between the interior and exterior over time led to the use of the void in the formation of the building's outer mass at the three-dimensional level so that the formation of the mass is based on that void which is called (designgenerating void) and the structure which is created by the void called (the spatial structure), as its formation depended on "geometry" and its methods of formation.
\end{abstract}

\section{Introduction}

The new prospect of digitization was reflected in various fields of architecture, including the architectural void, which is considered as a generator of design in the interface, in order to create dynamic space configurations that are compatible with the era of the digital revolution in which the boundaries between the exterior and the interior fade away. So the void that the research deals with is emerging from the interference between the exterior and interior voids. It is related to the context on one hand, and inside the building on the other hand, so the architectural void appears as a dialogue area between fragmented or segmented pieces, or as a spatial interlock and merging area to convey the state of architectural formation to a state of permanent formation to achieve interactive output through the idea of formal manipulation and the principle of deletion and interference between mass and void, thus impedes the monotony to create new relations between the contradictory parts. When the void participates

* Corresponding author.

E-mail address: shamms51@yahoo.com ( Shams A. Ameer) 
in the formation of the interfaces, it works within the fourth dimension which is represented by the time. Thus, there is a need to clarify the connection between the void and the digital architectural formation, up to the role and importance of the void in the digital architectural formation. Accordingly, the research problem has been stated as follows: (insufficient knowledge about the importance and role of the threedimensional architectural void and the mechanisms of its formation in the interfaces of contemporary digital architecture as a void that generates or creates the design within the needs of the designer and receiver). For the purpose of solving the research problem, the approach has been divided into five parts, the first of which was to study the basic concepts of the research "architectural void, and architectural formation in interfaces". The second: included building the knowledge framework for the formation of a digital architectural void. While the third focused on building the theoretical framework through the analysis of the literature and previous studies. As for the fourth: it dealt with the elected projects for the purpose of application. And finally, the fifth presented the conclusions and recommendations.

\section{The Conceptual Framework of the research:}

The theme discusses the concepts of architectural void and digital formation in an attempt to understand its effect on shaping the interfaces of contemporary digital architecture and its characteristics.

\subsection{Architectural Void:}

The paragraph explains the concept of void in two main aspects and as follows:

First: Linguistically and Idiomatically: the void in English is defined as the empty space or everything is empty and not filled or does not contain anything, or the state of being without something and a complete absence of the contents [1] and is defined by Al- Mawrid dictionary as the meaning of vacuum in the sense of loss or emptiness. Or void is a thing which is free or vacant. Al- Jami dictionary defines it as a vacancy or empty place and the plural form is voids. Al-Musbah al-Munir dictionary defines it as emptying something of another thing or removing it. [2] Aristotle mentioned in his definition of void as "a container for things". As for Plato, the void is considered in his theory as a continuous and constant quantum. Whereas the later theories of void were adopted on the basis of Euclidean geometry more than Aristotle's hypothesis and defined void as an absolute and infinite homogeneous element and one of the fundamental dimensions in the universe. After 1800 years, "Kant" considered the void as a kind of human understanding that differs and is independent from the subject, but in the twentieth century, «Descartes» gave an approximately clear concept of the physical space and this concept is still important as he considered any engineering is a human establishment more than being something in nature. Void is an intangible thing that has an emotional relationship with the human which controls it, expressing its thought and attitude towards the circumstances surrounding it. Thus, the theory of relativity replaces the three-dimensional idea with a four-dimensional idea in which the time factor directly participates. [3]

Secondly: The void in architecture: the architectural void is defined as the embodiment of the absolute general void interacting with human existence. Cheng says that the elements of form and void constitute the truth of architecture [4]. Lawson believes that the value of architectural work comes from the value of void, architecture and architectural voids accommodate, separate, structure, organize and celebrate human spatial behavior. "The role of architecture is to regulate the void and its structure," Lawson says. [5] The philosophy of void lies in considering it as a created void that the architect arrives to with a type of abstraction that creates a distinctive view that can be felt, and its influence, which increases in strength and weakness, changes depending on the nature of the formation of the void, and this is the essence of the architecture that the architecture should mainly seek. As for Lewis Khan, architecture is also known through the role of void in it and says: "it is a studied formation of void" [6]. Void is also considered as a three-dimensional space that surrounds us or an area of an architectural form. [7] Al-Dahwi explains that the effect of the abstract school on the concept of a void was through two aspects: an expressive abstract aspect and a material abstract aspect; the first called to reduce drawing to a group of a few signs of slight intensity, generating void through the interference between the inside and the outside and from a study of the relationship between void and time, which aims to abolish " the inside and outside dualism" as well as the non-identical and unstable formation; and dealing with void in continuous, interrelated or intersecting relations. While the "material" abstract side appears in achieving open and transparent void and achieving overlap between the inner and outer spaces [8]. From the above, it becomes clear that the void in architecture represents a framework for social and cultural forms, determined by the elements surrounding it and is within the formation of the mass at the three-dimensional level, and it results from studied relations of architectural formation with the aim of enriching the function or symbolic significance.

\subsection{Formation:}

The paragraph clarifies the concept of formation in two main aspects:

First: Formation in Architecture: the architectural formation is represented by the outside sensory appearance of materials which consists of a system of properties for the formative elements and sensory relations between them, whether in the horizontal level or volumetric or spatial formation. Architectural formation begins with knowing the sensory characteristics of the various regular forms, from which we conclude some values that control the relations between masses and architectural voids. The formative process is defined as the organizing of a set of elements within a ruling framework of relations and foundations that define how these elements exist in relation to each other and they are linked to two main goals, which are the utilization and beauty, where architecture represents a usable spatial space that meets human requirements. Modern technology strongly influenced those formative elements and gave a great deal of freedom and flexibility to the architectural formation. Architectural formation means formulating the architectural form in a way that results in new features and new relations, similar to the artist when sculpts the block, to bring out organized forms and areas that change the ambiguity and illusions into forms with distinct meanings and spirituality that are compatible with modernity and achieve communication between the formative elements and modern systems. [9] It is clear from the above that formation, in general, is the process of creation and innovation, that is collecting elements and placing them in a specific formation to give something with a specific function or meaning and unique characteristics, in which human thinking and personal experiences interfere.

Second: Digital Formation: the digital formation is seen as a set of methods which employ the computer not as a display tool, but as a generator for finding and transforming the form. The goal is to make the computer a designing tool in order to find a generating system that helps 
in architectural design, where the difficulty lies in finding the boundaries and variables that define the design process, as there must be a cooperative relation between the human mind of man and computer systems, and this cooperation can be achieved only through the use of logarithmic strategies that emphasize an integrative and dialectical relation between a person and a computer. [10] The digital formation is defined as the generative processes based on parametric values, the role of the designer is limited to deciding on the main axes that define the form, then unleashing the program in order to perform the computational operations which produce the final form. [11] Digital forms are defined as those forms which their design depends on the use of the digital language and the computer as a basis for the design. Later, these forms spread in various engineering and technical fields, so they came as an expression of experiences for a new generation of renewed theories of sculpture, architecture, and forms. They represent a new trend that is increasing and spreading, and this new idea has been reflected in various fields of architecture. [12] From the above, it is clear that the change in the design process due to the use of digital means has provided new design capabilities for the production of free and dynamic forms with endless capabilities in finding the form generated by digital tools. The architect in the digital design process uses computer models to manage the design process and the generative internal logic of the model generates the form, then the architect chooses the form from among the various possible forms that the program produces and this moved the architectural design from (making the form into choosing the form), as the digital generation process of the form opens up new horizons for architectural thinking and the resulting form.

\section{The Cognitive framework of the research:}

it discusses the formation of the architectural void from several basic areas which are the dimensions of the digital void, the architecture of its formation at the two-dimensional and three-dimensional levels, and explaining the strategies, mechanisms and rules of digital void formation in the interfaces of digital architecture, in addition to explaining the most important features and characteristics of void creation.

\subsection{The structural dimension of the architectural void:}

The void and mass represent an integral unit. They are inseparable. The structure of the void can only be formed by knowing the mass, and vice versa. By forming mass through the physical elements, the void is formulated, and by the difference in the relation between the void and the mass, several voids are produced (internal, external, and middle voids). The level of the relation between the void and the mass, i.e. the strength or weakness of this relation, can be determined by what is between the specific surfaces of the void. The flatter it is, the weaker the relationship and vice versa whenever the middle void emerges through its elements, that relationship strengthens. [13] The non-physical nature of the void gave it multiple capabilities for its relation to other voids, which allowed for a variety of design relations in different architectural works. [14] The idea of overlap and transparency appears in the formation of the void structure through the overlap in the future glass architecture. Interference weakens hierarchical models at all social and architectural levels, so interference is a multiple character. As it is possible to achieve the void formations in the design based on the basic design elements which include (rhythm, unity, proportionality). Technologies have a great role in achieving the architectural orientation, whether in terms of simplicity or complexity. With the required speed in construction and for the ability of some materials to form regular or irregular forms, they played a role in shaping the structure of the architectural void, and this was reflected in architectural works, complex configurations, and free and dynamic forms. [9] So, the term of void formation is used to refer to the capabilities of three-dimensional lines in interacting with the voids surrounding and within them. The linear formations which are characterized by being a separate entity in a void have a void activity that may appear as an element in which it is able to find a void. The three-dimensional spatial structures in addition to the spatial dimension, give a sense of the formal composition (volumes) and motion in a continuous integrated building unit and an unordered rhythm of its being in a specific environmental form and conditions. [15] It is clear from the foregoing that the structure and formation of the void result from spatial interference through the closure or openness between the mass and size, so the formed void is of high transparency and contributes to achieving integration and interference between the interior and exterior, and the use of the architectural void represents an evocation of the entire symbolic meaning as it gives the idea of division and expresses an idea in the mind of the designer and these ideas are multi-meaning to the recipient, thus the void exceeds the physical needs to achieve sensory and emotional needs. This led to the creation of an emerging corrective style that works within the three dimensions of the building without breaking the main composition of it, and employing these voids to achieve needs further than the aesthetic needs such as environmental needs to achieve vitality of the structure and creates interaction between visitors through motion and interference produced by the voids in the composition of the building.

\subsection{Geometry at two-dimensional level (2D):}

Geometry is the science that searches in mathematical concepts related to line, surface, square, congruence, equivalence ... etc. as well as looking at the application of these relations in the practical aspects of life. It is also a science that studies space and magnitude, and it is concerned with the position, form, area, and size of form and solids without addressing their physical properties. The term solid geometry is the engineering that deals with forms and solids in a three-dimensional void. Dr. Khaled Mahmoud proposes the geometry, or what he calls (the architecture of void forms) by explaining the link between the architectural formation of buildings from ancient times with the basic geometrical special forms. With the emergence of the digital revolution and its applications through that trend in the fields of architecture and design, the innovative treatments for these basic geometrical spatial forms and in order to achieve various purposes and goals, ranging from activating the building's functional efficiency or raising the efficiency of its climate and environmental treatments, or even just to those same formative and visual goals, as well as other purposes and objectives. [16] Four basic vital relations can be distinguished to form an architectural void, including the following:

First/ Void within void: A large void can contain a smaller one within its volume. Therefore, we find that the spatial and visual continuity of the two voids is easily embodied, but the smaller content void depends on the larger. [4]

Second/ Interlocking or overlapping voids: A spatial interrelationship is produced by overlapping two spatial domains, which results in an area of a common void. The intersection of two void forms creates a common void, with characteristics that differ from both voids. This intersection somehow affects the properties of the two voids as well, 
and the area formed by the intersection can be equally dependent on both voids, so that the three voids appear to be of one space, or the common space can be part of one of the two voids and completely taken out from the other void. [4]

Third/ The adjacent voids: The degree of visible and spatial continuity that appears between two adjacent voids depends on the nature of the surface that separates them and connects them together. It may include a change in the level of variation in the surface material or in the fabric (structure) between the two voids. [4]

Fourth/ Voids associated with an intermediate void: Two voids separated by a certain distance can be linked to a third, intermediate void. Here, the visual and spatial relation between the two voids depends on the nature of the third which is connected with them by a general link. The intermediate void can differ in terms of formation and orientation from the other two voids to express the Fig. 1-b Void as a kinetic optical link element in the 3D plane [14] interconnection function between them, and the formation of the intermediate void may be residual in nature and specific as a result of the configurations and directions of the other two interconnected voids. [4]

According to the foregoing, it is clear that the formation of the void at the two-dimensional level involves clear rules between the elements, out of the idea of simplifying the components, preserving the form of the voids, and making use of those voids without waste. Therefore, geometry must be studied and understood to be adopted as a generator of design and an architectural formation unit which shapes the outputs of contemporary architecture.

\subsection{Geometry at The Three-dimensional Level (3D):}

Void is defined in geometry as what is determined by three orthogonal dimensions, so it is known to have dimensions of length, width, or height, and the proportions that link these dimensions are recognized, as well as the ratio of the dimensions of the void to the ratio of its human dimensions [14]. In this context, three-dimensional forms are defined as forms which contain points, lines, surfaces and bodies in a blank image, among which is the solid form which is considered one of the strongest forms as it is a mass that is handled by sculpting, removing or adding and it can be called a structural form or complex compound which is based on a group of connected bars together in the horizontal, vertical, diagonal or any other direction to make the final form, and finally, the surface form which consists of a group of horizontal, vertical, inclined or rotational surfaces that can be separated from one another or interlocking. [9] The space can be defined in the interfaces as being the incubator of the mass in coexistence and harmony so that the mass does not overwhelm the space and the space does not weaken due to the strength of the mass. Burnham believes that the void is an effective and positive element for its ability to connect volumes to each other as if it were a connecting force or a communication link like any other solid material with its properties and effectiveness because it is a structural part of the same form. The void is not only part of the cosmic space that surrounds only the form, but rather a substance itself. [17] The void resulting from the positioning of forms must be treated with the same importance of the forms, so it is called the Negative Space when it does not represent a certain dimension after the forms are positioned in it, and it is called the Positive Space if the form of the void that is trapped between the forms has a certain form. [6] The three-dimensional theory (solid-void theory) shows that the volumetric voids formed by the positioning of solid forms are of a higher importance than these forms themselves. The three- dimensional void is considered a positive space if it has a specific form and gives a sense of borders or is a threshold for moving from the outside to the inside. [6] The void is formed by deleting the space of the elements that it is defined by. If the boundaries of the void are clear, defined, and identifiable between the inside and outside, then the void formed is called a defined space. Otherwise, it is considered as an undefined space. [14] There is a great diversity in the methods of organizing building mass to confirm the spatial dimension between them. It is necessary to know the organization of the masses and the relation between void and solid, to reach the required design goals. The following figures illustrate some methods of organizing the mass in order to reach the required level. [18] When two closed voids intersect, the result is the volume formed by the merging of the two voids together, and there are major possibilities for the result of the intersection, so sometimes the void forms a central connecting element between the other elements. Sometimes, the void is a visual kinetic element when it is in the three-dimensional plane, often extending over the entire height of the building and is often characterized by coverage of a different nature in terms of form or transparency or the possibility of opening to the outer void from the rest of the voids, which gives the void distinct characteristics. The true value of this void does not come from its utilitarian only, as it is not of a necessarily major function, but its role in connecting the voids and the volumetric and visual composition of the design is what gives it the value for being the heart of the work or the engine of the design. [14]
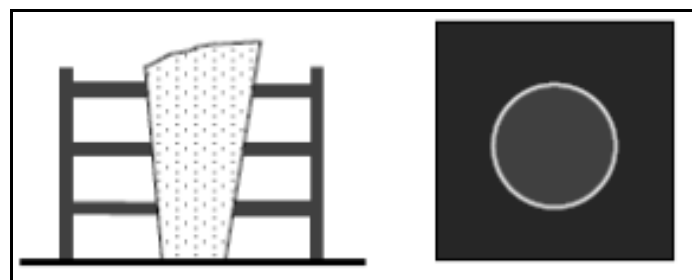

Figure 1-b. Void as a kinetic optical link element in the 3D plane [14]

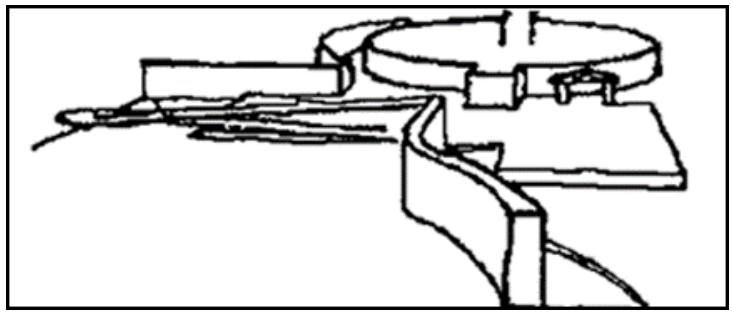

Figure 1-a. Sculpture in the Block [18]

It is clear from the above that the role of the three-dimensional void with its various forms in the design process is to connect and regulate the relation between other voids and form elements. So this process is affected by the nature of the geometrical form of the void, so each form has its own characteristics and controls the relation between the elements, so the form of the void affects the relations between the void and the design elements.

\subsection{Interfaces and formation of digital architecture:}

Displaying a module of external structural elements in the interfaces of free formations enriches these interfaces and organizes the formation and helps to define the non-standard form of the curved walls by emphasizing the three-dimensional curves, accordingly, our understanding 
of these formations increases. [19] The spatial formation system has changed from being central to multiaxial design and formation and deviated from the traditional design network. It has also shifted mainly from the regular and the basic geometrical forms to the irregular, folded, deformed, and disjointed forms to shape a new, stand-alone nonEuclidean system which was reflected on the interfaces. [20] The use of the modular system which is clear on the interface gives the envelope layer several characteristics, including:

- The ability to amend and configure the interface modules.

- The module allows manipulating the scale of the building "change the beholder's perception of the scale of the building".

- The module generates styles that regulate the outer envelope, enrich it with rhythm and hierarchy, and make it visually enjoyable.

- Shows the structural elements in buildings.

- In free and irregular formations, the display of structural rib modules leads to organizing the formation and determining the nonstandard form of the building.

As for the types of the modular network, they include: (the systematic modular network - linear - diagonal - radial circular - the modular network which follows the geometric form - the spatial modular network). [19] If the depth and the modular characteristics are combined in the structural elements on the outer envelope, they give the building spatial formations and a dynamic interface in the formation. [21] The irregular void formation led to the generation of the concept of vital, malleable void, which is embodied by the flexibility to organize and liberate the elements of the void from explicit geometric relations, where the malleable forms are related to dynamic effects, and thus the void is full of motion and has no specific systemic form or any geometric axis. [22] The void is formed by combining two volumes or two closed voids which gives a distinction to the void and is often added to attract attention to an important point of the design. This void is directly related to the axes of external motion, and therefore makes a transportation void between the outside and inside of the building. When an open void intersects with a volume, the result is the process of cutting off the joint part of the two forms. In other words, the process of the intersection of mass and void, is a process in which the mass is being emptied to fit that void, and the dimensions of the void are close to the dimensions of the internal volume so it is highly dynamic and has a central polarization point. When the dimensions of the void are greater than the dimensions of the volume, it becomes more dynamic information, and the architectural ties between the surrounding masses are weakened and the design becomes closer to the urban formation. The void creates a space and a dynamic link between the volumes that have less openness to the void. [14]

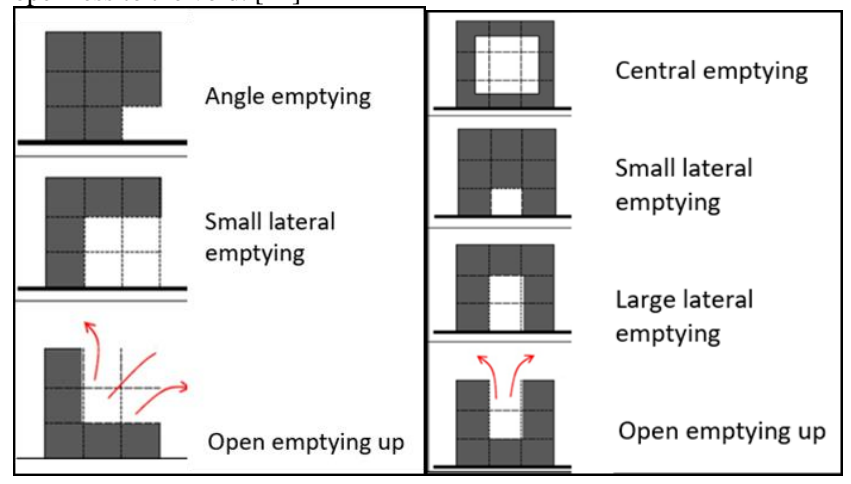

Figure 2. Forming a Void in Facades [14]

\subsection{The digital dimension of architectural void (digital void):}

In physics, the structure of the digital void consists of an added void or a separation area (a void between masses), the formed void is related to the mass, whereas the separation area is related to kinetic energy, so the separation void collects about three different forms: (the non-mixable area, binary partition area, and the binary grid area of the threedimensional void). [23] In the digital architecture, the importance of adopting (CAMCAD) has been noticed to create hypothetical forms that combine natural forms (organic and inorganic) and engineering (irregular and nonlinear) with correlations similar to those in biology and cosmic science to create free forms with unique spatial configurations or so-called spatial creation, through containing the void of the event and adding the time as a fourth dimension to the void, as architectural ideas are developed in digital data by interactive and dynamic means which enable the designer to explore the relation between the technique of the form and its development by computer, as well as the choice of components, materials, texture, and structure of the form, in addition to the ease of the processors for the designer. [24] The digital model which is formed according to the concept of self-organization, for basic units over which energy is projected to overlap with each other to form a specific pattern of the form, is subject to transformations at multiple levels of the form pattern at the level of the parts and their relation between them and all others with the diversity of the relations between them by attraction or repulsion. Transformations occur in the relation of the part to the part of identical elements from states of repetition and transit. As for the transformations of the level of the relation of the part to the whole, it produces positive and negative elements. As for the positive elements, they represent the emergence of a specific formation (addition), and the negative parts work as the background of the elements which generate a void which is considered a container and organizer for the rest of the elements by (deletion). This is what happens in real life, with the growth of spatial geometrical forms from simple rules in which the parts are formed with high engineering at the level of the part and coherence at the level of the whole. [25] The digital void is considered as a part of the imaginary reality of the building, as it creates the different threedimensional spatial formulations according to the factors of time and motion, and clarifies the form of one of the applied tools of the virtual reality. These applications fall within the scope of how to show architectural work as well as to evaluate the design process in greater depth for creative persons and judge them before the implementation. The digital void is formed by two states of static and dynamic. [26] According to the above, it became clear that the elements of architectural formation are affected by digitization, especially the architectural void, as its dimensions have changed due to its association with time and has become a fourth dimension of architecture, and therefore the dimensions of the digital architecture outputs have changed from the traditional dimensions of (length $*$ width $*$ height) to the digital dimensions represented by (length $*$ width $*$ height $*$ time).

First/ The Static digital void: The static void is designed by organizing the void elements in a formal relation, i.e. symmetry can control the whole void, as it is an independent void with respect to adjacent voids, and does not usually give a sense of direction and does not suggest any motion in it. The static void may be a memorial measure independent from the viewer, but it may be influential in its size, and the viewer can realize all the void at the same time from one standing point. [22] Avoid is formed by the deletion or cutting off of space by surfaces or elements that define the void and give to its properties. Thus, the formed 
void becomes of the same of even more important than those elements forming it. [14]

Second/ Effective dynamic digital void: The effective dynamic void is designed by freely organizing the elements of the void away from any formal constraints such as symmetry. The dynamic void gives the viewer a sense of excitement and expectation i.e. the entire void is intended to suggest motion and diversity, as the void is characterized by the flexibility that has become a requirement and a necessity to face the accelerating rate of change, that is, elements can be added or removed without affecting the cohesion of the void, and it means that the elements and their mutual relations are variable. The flexibility can be easily achieved by means of a void division or closure degree and through the presence of strength and motion in time. [22] The force is considered as the condition or the reason for every motion, especially the twists, distortions, and voids in the architectural form that provide a dynamic model based on Animation and Morphing. It is possible to take advantage of the software of digital moving entities to generate the form and its transformations based on the cinematic model, to exclude power and motion from the articulation of form through the mechanisms and techniques of visualization and the use of options and full menus of motion-based modeling techniques such as keyframe, key form, Kinematics, Inverse kinematics and forward kinematics and others. [27] As per the above, it is clear that the digital void creates the different threedimensional spatial formulas through adding the two factors of time and motion, and is considered one of the applied tools of virtual reality, which makes the architectural elements more light, transparent and graceful, and features the outputs with the absence and fading of boundaries between the inside and outside in the digital architecture. And therefore, the importance and the role of the void have emerged in the digital architectural formation in contemporary architecture.

\subsection{Strategies of void formation in the digital architecture interfaces:}

Form generation strategies rely on the structure of the rules governing the form generation to allow the architect to explore meaningful bodies within more complex engineering formats that depend on the hidden capabilities and commands of digital software. [28] The digital generational approach is characterized by providing mathematical techniques for formal generation processes, in which the designer interacts with complex mechanisms that deal with the emergence of forms derived from rules, principles, and generative relations. Bodies and forms are the result of pre-formed and preformed generation processes, providing control and options for the designer to choose solutions. Often these processes are based on evolutionary rules and principles of natural or engineering generation. Both approaches may be combined in some formation models to produce complex models which combine them both. [29]

First/ Void strategy as a generator of the design: The design according to "CHING" is a deliberate act or intended attempt that starts from recording the problematic properties and studying their content since the nature of the solution depends on how the architect sees the problem. [4] According to "Wong,", the design is a purposeful visual formation process, which means it has a utilitarian purpose and good design is the best possible visual expression for the essence of "something", whether it is a message or an output, and to complete this achievement efficiently, the designer must search for the best possible method to form, design, distribute, use, or link this "thing" to the surrounding environment, so the design is not only expressive but rather functional. [30] From the definition of design, it is possible to conclude the location of the void in the process, starting from the process of analyzing the problem by the void, which will lead to finding the appropriate void solution, as void is the generator of the solution proposed by the architect for the design problem. [14] The void which link the architectural work and collect the rest of the elements is often the one which evaluates the architectural work, i.e. gives it an architectural value, since the architectural work is evaluated through it. It carries the message of the architect which wants to communicate through design, and it also gives a character to the building, as it is the title or identity of the building as a whole, and that's why this void is considered important. We cannot be certain that such a void exists in all buildings, but looking at the distinctive and valuable architectural works, we must find that generative void, and its function and location of the designs differ from one work to another as per the calculation of the architect vision and the dominant intellectual concept of his time. [14]

Second/ Void strategy as an architectural formation unit: The void is the essence of the architectural work and a major component in the formation. It is not just a result but the starting point of the design process. [14] Void is a concept that is perceived in large dimensions such as "nothingness" or "infinity". An architectural void is a concept viewed based on "human scale," and it has architectural characteristics [7] Moreover, avoid is a unit of formation which participates in the design of work and becomes the main generator of the void relations between the other formation units. The formation unit in the architectural design is a void unit and consists of elements that form the boundaries of this void. [14] The void itself is a flexible element and this element is used as a method of void formation, and the outside form of the building includes the following variables: (boundaries, motion, construction system, envelope, type of construction, construction process, energy, environmental control and general perception). Form is one of the variables of the design problem, and it is the variable that is controlled by the designer, and we must remember that solutions to design problems are an agreement between need, environment, and form, in addition to the costs. [31]

Third/ Void strategy as a mechanism for forming the interfaces: Mass and void in are among the most important formation elements in the work, followed by the motion and color, then balance and rhythm, and diversity in forms and sizes of the formative components of the work, which gives the void model formative, expressive and aesthetic values that can be felt and perceived by the viewer. [32] The void specifying elements and what is contained within are not a plate within a frame but rather a field that has a variable balance force, and these forces grow when the format of the boundary is adequate or go with one axis instead of being independent. The human being does not need to accurately record all the elements and parts to form an embodied idea of the void. [22] The void which lies within the outer body of the mass is not just a part of the cosmic void but rather a substance itself, in the sense that it is a structural part of the form which can connect the parts of the work to each other as if it were a connecting force like any other solid that enters in the formation of work. It is the void that specifies the form, properties, and dimensions of the form. [15] The model today includes many elements such as the identity of the designer, ideas, and any image or concept that he wants to show, in addition to design decisions and functional requirements. In the process of digital formation, different methods can be followed to form the model, one of them is that the designer defines a concept and designs the surrounding model based on it, so the model reflects a specific idea or symbol in the mind of the designer. 
[7] The main way to solve the design problem begins with analyzing of the concepts related to the problem, and one of the most important steps that must be taken is visualization, where the thought refers to a specific concept, which is an important means that gives way to think and then to design. [7] Some designers create the model using voids, thus "the void" appears as a concept that has priority in the main idea. It can be said that this method can be described as "a concept using design " or "conceptual design" where the thought comes before the form. The most important point is to ideally reflect the concept which is needed to be emphasized. During the conceptual design process, "void" is one of the prominent elements in the formation of the model. When designing forms with voids, designers express the concept that they want to reflect through the use of "the void", which generates the so-called void configurations. [7] The spatial three-dimensional form is known as the three-dimensional body, and is present in the space of the void, and it is characterized by mutual interactive relations with all its types such as the penetrating, surrounding and permeable voids. The void is considered one of the form types, as it is not something different from form, but an ethereal form in which motion is easy, and the concept of the void has evolved to go beyond being an intangible field in which forms are perceived to be considered an element of the same importance as the form. [32]

As per the above, it became clear that digital technologies and the development of materials have contributed to the possibility of making the architectural void one of the mechanisms which create the void formation in the interfaces. Furthermore, we find that there is an emphasis on the aesthetic role of void formations in enriching the creative and expressive values of the contemporary sectors and different types of voids in the interfaces of contemporary outputs, including the following:

1. The Penetrating Void: It is the void that penetrates the form and extends beyond it, so appears what is behind, and this type of void is called the absolute or endless void, which its end cannot be tracked by the eye, and allows the passage of light through it, and reduces the weight of the masses and gives new dimensions to the form and it works within the third dimension. [15]

2. The Formed Void: It adopts the mass as a determinant and creator for it, considering the void as a result of the architectural design. Or the design starts from the void as a basic formation unit emphasizing on showing the void and hiding the structure.

3. The Structured Void: It consists of the formation of the structural structure, where the basic structural system of the building exists, or the structural system is more visually controlling in the building. [21] The innovation and creativity in determining the form of the structural formation, whether it is a separate or continuous construction terms, gives flexibility in the design idea and gives creativity in the formation and consistency of the masses that make up the output. [19]

4. The Surrounding Void: The void which exists within the external body of the mass is not just a part of the cosmic void but rather a substance itself, which means it is a structural part of the form that has the ability to connect parts of the work to each other as if it was a connecting force like any other solid that enters in the formation of that work, which is the void that determines the appearance of the form as well as its properties and dimensions. [15]

5. The Four Dimensional Void: The four-dimensional void is a highly visualized manipulation of forms that gives the feeling of time distance. [15]

6. The Creative Void: The concept of the creative void refers to ignoring the void of the spatial environment in which the elements exist, and creating another void, so we a kind of conflict occurs with the nature of the spatial natural environment of the elements. [33]

From the above, it becomes clear that the role of the void as a mechanism in forming interfaces is through the manipulation of solid forms and bodies in a free or formal way, and there is more than that behind this formation, as this process came not for form or aesthetic purposes only, but rather to achieve a specific goal or need.

\subsection{Mechanisms of void formation in the interfaces of digital architecture:}

Architecture is a two-component formation between masses and voids, and each element has its own visual characteristics of the final formation. The architectural formations also reflect the principles controlling the relation between its elements, which are considered the basis for this formation. [9] Among the most important mechanisms for finding the architectural form in the outputs of contemporary digital architecture are:

1. The superposition mechanism between architecture and computer.

2. The reduction mechanism in the reference or the elements or data entered using the digital technology.

3. The abstraction mechanism which contradicts the traditional forms of architecture.

4. The interpretation mechanism using sculptural and ambiguous forms to express the designer's thought in designing and communicating with the recipient through multiple interpretations.

5. The amplification mechanism on the scale by exaggerating in the creation of extreme forms to produce works similar to the memorial text.

6. The communication mechanism between the inside and the outside to achieve the characteristic of transparency in design work.

7. The addition mechanism, i.e. adding elements or shapes with the aim of increasing the expressive strength of the building. [34]

8. The deletion mechanism for an object that is been disintegrated into its engineering elements and provided through a simple form to create a relation between the mass and the void. The architect may interfere in the deletion of the projection, the interface, or an architectural form to create a contradiction between the positive mass and the negative void resulting from the deletion. In the projection of the Arabian building, a middle or side part of the mass is deleted to produce an interior yard to enjoy the sky through it, unlike its other beneficial advantages. In the interfaces, parts of them are emptied into open terraces, as in the National Bank of Saudi Arabia in Jeddah. [9]

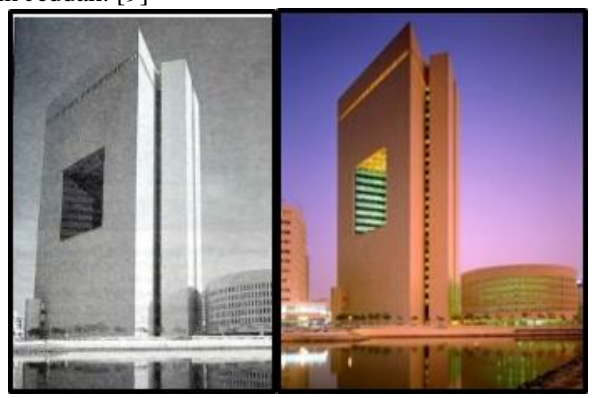

Figure 3 Design with deletion - The National Bank in Jeddah [9]

9. The deletion and addition together, i.e. forming one mass by deleting some parts of it, and adding complementary masses over it or adjacent to it. This mechanism is frequent in Islamic architecture 
to create a unified mass formation without tending to the single simplification. Addition and deletion which can also be called negative and positive, give a contradiction in formal treatments, and this treatment has become a distinguishing feature of contemporary architectural form by combining the two opposites, and addition and deletion may be intertwined. [9]

As for the mechanisms of finding the digital structures, they include flexible wrapping, bending and adopting innovative structural systems through reorganizing the structure in a new method and mechanism of penetrating, fragmentation, transformation, separation, structural synergy, employing the laws of nature, playing with tracks through the mechanism of manipulating the relation between the elements that make up the structure, or manipulating the structure and changing it, or adopting structural lightness depending on the nature of the material used. [35] According to the above, $t$ turns out that with the increase in the ability of material and construction systems technology or digital technologies, the lightness and transparency of the construction and architectural elements increase, and some elements become able to change their characteristics to achieve technical and technological goals. So the development of building materials in contemporary architecture, in addition to many inventions has given new horizons for the architectural ideas as some new architectural materials, such as steel, aluminum, and titanium, with their advanced properties and great flexibility, have helped in covering spaces and surfaces of various formations and areas.

\subsection{Features and characteristics of the spatial structure in the interfaces:}

The quality of the form lies in its organization, so the model is produced through the possibility of achieving large voids with less support so the aesthetic value of the formation of the output depends on the continuity of the relation between the inside and outside and is generated through the balance of structural components, and by relying on several factors to achieve continuity through the continuity between the outside and inside and the continuity of light and shade. [36] The change in the spatial formation was through its representation in a twodimensional dot matrix (the projection of void or formation), as it was a regular formation from one of the basic forms (square - circle - triangle), changed to regular but less central forms of representation and then noncentral formations followed by spatial formation with two different spatial grids so that the representation becomes partially or completely irregular, up to the fragmented spatial formation which characterize the void, composition and design of the architecture of the last century from the middle to the present. [20] All these factors, building materials, and contemporary construction methods have affected the features and characteristics of the architectural void, and therefore affected the characteristics of the output. The most important characteristics of the resulting form of the void formation are the following: (symbolism and abstraction in the digital void formation of the interfaces, the absurdity in the digital void formation of the interfaces, the visual anxiety in the digital void formation of the interfaces, the dynamic formation in the interfaces of contemporary digital architecture, Solid and Void and interstice).

\subsection{The digital architectural void as a needs achiever:}

Scientists classify human needs according to a pyramid called the pyramid of needs, or what is known as the Maslow pyramid. It divides these needs into ranks according to their importance to humans, and architecture comes to meet higher needs more than those essential. [5] The nature of these needs and how the architectural void will handle them, will be addressed. If the adoption of the void as a generator of the design or as an architectural formation unit in the outputs of contemporary architecture did not come without a reason, it came to achieve an objective or specific need. There is a diversity in the use of the void which forms the interfaces, according to the different methods of formation and the need that it achieves, as "the form and the void are complementary to each other to achieve a specific job or need".

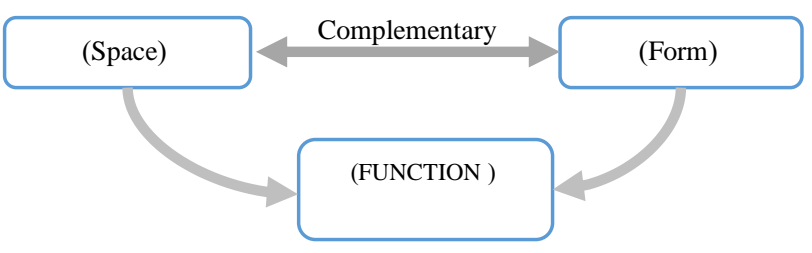

Scheme 1 Integration between shape and space to achieve a functional need (Prepared by the researchers)

First/ The void as a symbolic and aesthetic need: The void here is being formed to express a specific idea and highlight aesthetic aspects in the formation of the building. King Abdullah House for Culture and Arts in Ras Al-Ain region, in the Jordanian capital (Amman), is considered as a meeting place for the advancement of the artistic and cultural scene in the Kingdom, so the design of the building was made featuring Al- Petra pink rocks. On her inspiration about the design of AlPetra rock, Hadid said "Petra is an ideal symbol for the successful architectural interplay between architecture and nature". The contemporary architecture seeks to emulate nature by constructing the building through to interplay with the detailed aspects and elegance of nature. Hadid sought to simulate the beauty of the pink rock, which was drifted and drilled to get along with nature, and make natural waterways to interact with the nature of the place. From this natural aesthetic element in Petra, the natural passageways were designed to connect the building with the public square and connect the outside with the inside. Hadid wanted to give a distinctive brightness to the building through the void which extends to the height of the building to show the interior parts, and reflect a sense of dynamism to the shape of the building from the outside. [37]

Second/ The void as a functional need: The function of the voids in the designs of Zaha Hadid is considered a special function as she used them for design purposes to link the exterior design of the building with the interior design, as she depended in her designs on the irregular or striped openings that show the light from the inside in a way connected to the external shape of the building, such as buildings with full glass interfaces to enrich the inside of void with the different natural lighting effects and the associated thermal effects of the space. In the CotaiMacau, a Tower and Hotel project, designed by the architect Zaha Hadid, which was constructed of steel structures, with a mesh wrapped on the interfaces that form a series of organically- shaped voids. The exposed exoskeleton of the tower enhances the dynamics of the design, and the structure forms a void at the front of the building and encircles it. To achieve the creative aesthetic values. [37] 


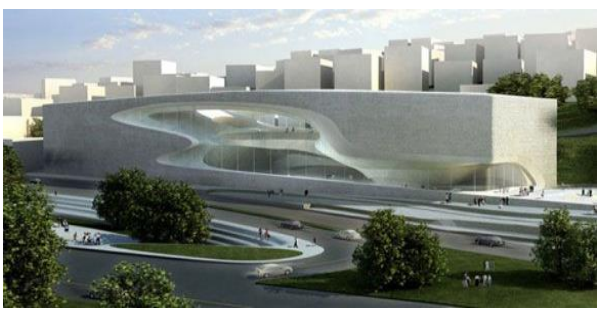

Figure 4 King Abdullah House for Culture in the Jordanian capital

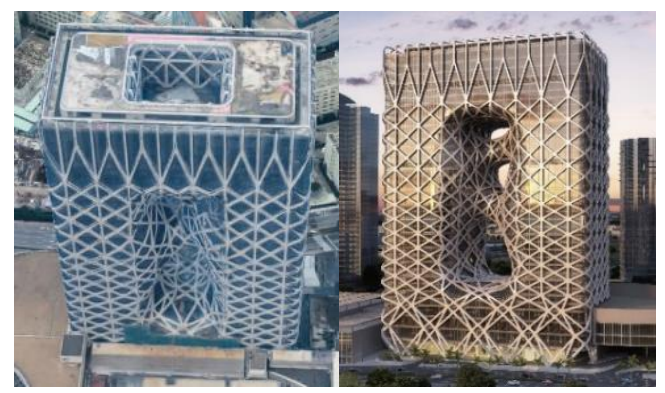

Figure 5 Tower and Hotel Project in Kutai - Macau

Third/ The void as a structural need: digital technology and digital manufacturing techniques contributed to the creation of modern construction systems which are considered as a revolution on old construction systems such as geodesic domes, spatial structures, extravagant structures, inflatable structures, cable systems, metal framework structures, fabrics, and light films. They enabled the architect to show the main construction elements, whether in a void or a mass, and to use them as final elements in the building without hiding them or covering them with other materials. [38] The void was formed here to reduce the weight of the facility by removing the extra loads through the digital technologies and algorithmic design programs, and the expression of the "structural system function" that achieves flexibility in the limits of the void, and making the building a mass that defies gravity. [16]

Fourth/ The void as an environmental need: The void has been used to achieve a specific environmental need by providing ventilation and lighting for the facility and taking advantage of the surrounding environment to reduce the buildings 'energy consumption and integrating the building with nature and making architecture part of the natural environment. As environmental formation is achieved through several methods with the aim to take care of the energy and utilize it in buildings and the outer envelope (interfaces) by employing energy sources and sustainable materials in the formation of interfaces. Among these methods, is the vertical void, which can be achieved through emptying some of the built-up areas and preparing them for agriculture. [9] The Bahraini Trade Tower project in Manama is an example of this. The formation method of energy sources has been applied in the Tower through placing the turbines in the space designed between the two sides of the tower, as the buildings were designed in the form of a sail on both sides to direct the winds through the gap to provide the acceleration of winds that pass through the turbines. [9]

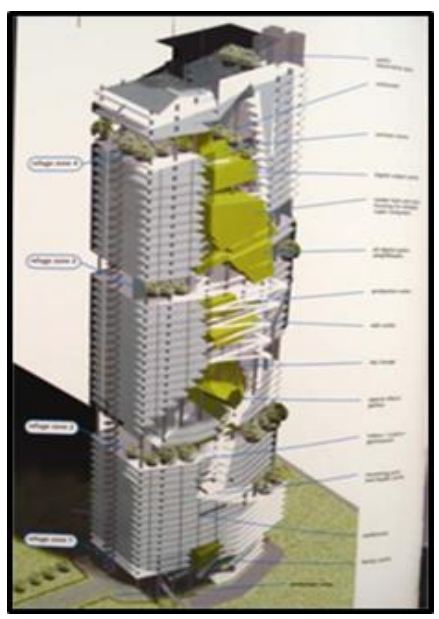

Figure 6 vertical discharge in tower buildings

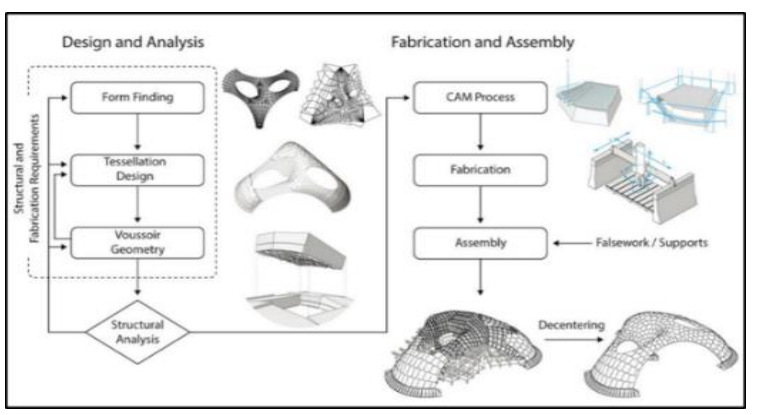

Figure 7 The vacuum as a structural need

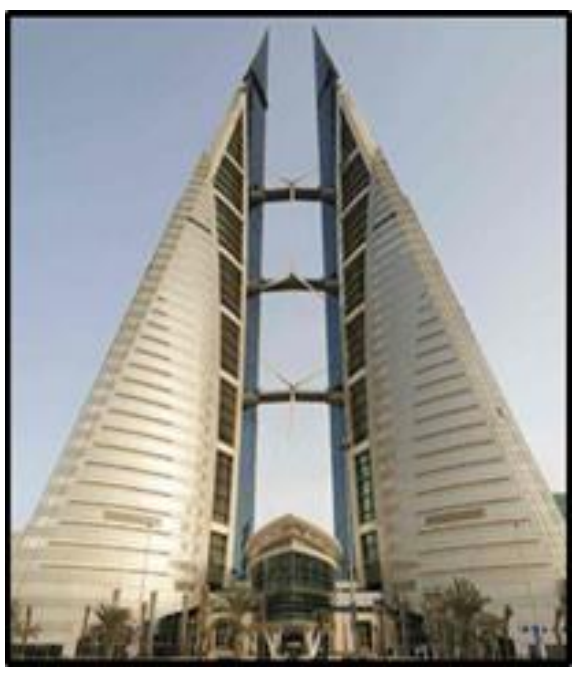

Figure 8 Bahrain Trade Tower project

\section{Theoretical framework:}

This topic deals with the presentation of a set of previous studies to extract the terms of the main and secondary theoretical framework and its possible values, and as illustrated in the Table 1. below: 
Table 1: It illustrates the previous literature and its main and secondary and its possible value. (source: prepared by the two researchers).

\begin{tabular}{|c|c|c|c|}
\hline \multicolumn{4}{|c|}{\begin{tabular}{|c|}
$\begin{array}{c}\text { The } \\
\text { study } \\
\text { title }\end{array}$ \\
\end{tabular}} \\
\hline 1 & 层 & $\begin{array}{c}\text { It dealt with the concept of the void in } \\
\text { architectural form, as the form, space, and voids } \\
\text { are the basic elements in the architectural design } \\
\text { process, and presented the features of } \\
\text { transparency and permeability. Where the voids in } \\
\text { the architectural form are classified into two main } \\
\text { titles through the method in which the model was } \\
\text { created: cognitive and functional voids. Cognitive } \\
\text { voids are related to the perception and used to } \\
\text { create different visual effects, while functional } \\
\text { voids are created to meet specific needs and } \\
\text { desires. The study further classified the cognitive } \\
\text { voids into three sub-titles: (conceptual, } \\
\text { perceptual/visual, sculptural/memorial), and } \\
\text { showed that the perceptual voids are associated } \\
\text { with the transparency. While the visual voids are } \\
\text { related to permeability. }\end{array}$ & \begin{tabular}{||c|c} 
& \\
Void types \\
$\mathrm{n}$ & Transparency \\
Permeability \\
Adoption of \\
digitalization \\
Spatial \\
formation \\
Deletion \\
Reduction \\
Void as \\
functional need \\
\end{tabular} \\
\hline & 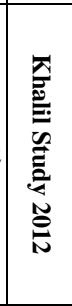 & $\begin{array}{l}\text { The study emphasized the role of digital } \\
\text { technologies and technological development at the } \\
\text { design and implementation levels. It led to the } \\
\text { emergence of new formation rules in architecture } \\
\text { called (digital formation rules), which affected the } \\
\text { architectural output, so its transparency and } \\
\text { dynamism increased in the light of these } \\
\text { developments and the lack of weights of } \\
\text { construction materials used for the ability to } \\
\text { simulate them. }\end{array}$ & $\begin{array}{c}\text { Transparency } \\
\text { Dynamic } \\
\text { output } \\
\text { uniqueness } \\
\text { Abandon the } \\
\text { standardization }\end{array}$ \\
\hline \multicolumn{2}{|r|}{ 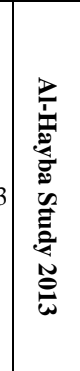 } & $\begin{array}{l}\text { As a result of the state of architectural creativity } \\
\text { presented by contemporary digital technology in } \\
\text { the fields of terms for the architectural formation, } \\
\text { such as the orientation towards the production of } \\
\text { (deconstructive) architecture, (basic geometric } \\
\text { voids) and others. The innovative treatments such } \\
\text { as deconstructing, reconstructing, overlapping, } \\
\text { and shattering these basic geometrical voids with } \\
\text { the aim of achieving various purposes and goals } \\
\text { which range from activating the building's } \\
\text { functional efficiency or raising the efficiency of } \\
\text { its climate and environmental treatments. }\end{array}$ & $\begin{array}{l}\text { Absurdity and } \\
\text { chaos } \\
\text { Visual anxiety } \\
\text { Deconstruction } \\
\text { and } \\
\text { reconstruction } \\
\text { Overlap and } \\
\text { shattering } \\
\text { spatial structure } \\
\text { Digital } \\
\text { formation }\end{array}$ \\
\hline & 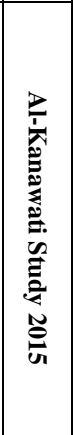 & $\begin{array}{l}\text { volumetric and functional formation relations, and } \\
\text { therefore it is the beginning of the proposed void } \\
\text { solution to the design problem. The void is an } \\
\text { architectural formation unit and is the most } \\
\text { important unit in formation, considering it as an } \\
\text { organizer of the relations of other units and thus a } \\
\text { generator of the design. The void acts as the } \\
\text { organizer of the linking relations between other } \\
\text { elements in the design. The void acts as a } \\
\text { functional need, and it acts as the organizer of the } \\
\text { formal linking relations between the elements, or } \\
\text { as an aesthetic need, thus serving as a framework } \\
\text { for the urban scene behind it. }\end{array}$ & $\begin{array}{l}\text { Void strategy as } \\
\text { an architectural } \\
\text { formation unit. } \\
\text { (Void/Solid) } \\
\text { (Absent-present) } \\
\text { The void as a } \\
\text { functional or } \\
\text { symbolic need. }\end{array}$ \\
\hline 5 & 交 & $\begin{array}{l}\text { void in space, in terms of the circumference of the } \\
\text { void and the things surrounding it. The effect and } \\
\text { importance of the void on the architectural design } \\
\text { as well as the structural, functional and } \\
\text { environmental effects of the resulting voids in the } \\
\text { architectural (forms/voids) were emphasized and } \\
\text { explained at three levels depending on the form } \\
\text { and function: The effect of the void on the form. } \\
\text { The effect of the void one the interior space. } \\
\text { The effect of the void on the exterior/urban space. }\end{array}$ & $\begin{array}{l} \\
\text { Permeability. } \\
\text { Interactive. } \\
\text { Unit. } \\
\text { Complexity and } \\
\text { contradiction. } \\
\text { Sculpture. } \\
\text { Deletion and } \\
\text { addition. }\end{array}$ \\
\hline
\end{tabular}

The study gave a clear conception of the expressive relation between the external formation and the internal void and its effect on the recipient, and studied the intellectual approaches morphology. 年 to the relation between the external formation and Static and ? the internal void at the philosophical and design Dynamic voids. 6 levels. The study also showed that employing the mass and void. principle of integration in architecture requires an Mechanisms of ب̂. confirms this intellectual compatibility and $\quad$ contradiction achieves the visual enjoyment for the recipient.

Based on the foregoing, the terms of the main and secondary theoretical framework and the possible values can be clarified as they were extracted from the knowledge framework and previous literature, as shown in the Table 2.:

Table 2: the terms of the main and secondary theoretical framework and the possible values. (Source: Prepared by the two researchers)

\begin{tabular}{|c|c|c|}
\hline $\begin{array}{l}\text { Main } \\
\text { Terms }\end{array}$ & Sub-term & Possible variables and values \\
\hline \multirow{16}{*}{\begin{tabular}{|c|} 
Digital \\
Void \\
Formation \\
Strategies
\end{tabular}} & \multirow{4}{*}{$\begin{array}{c}\text { Void strategies as a } \\
\text { design generator }\end{array}$} & $\begin{array}{c}\text { Computer Generation (Algorithm } \\
\text { Engineering) }\end{array}$ \\
\hline & & Digital Modeling (Self-Improvement) \\
\hline & & Simulation \\
\hline & & $\begin{array}{c}\text { Synchronization (time as a fourth element of } \\
\text { the void) }\end{array}$ \\
\hline & \multirow{3}{*}{$\begin{array}{l}\text { Void strategy as a } \\
\text { mechanism for } \\
\text { forming interfacing }\end{array}$} & Void formation \\
\hline & & Manipulation \\
\hline & & Reduction \\
\hline & \multirow{2}{*}{$\begin{array}{c}\text { Void strategy as an } \\
\text { architectural } \\
\text { formation unit }\end{array}$} & Hide and show \\
\hline & & Deletion (hiding some parts of the mass) \\
\hline & \multirow{7}{*}{$\begin{array}{l}\text { General } \\
\text { mechanisms for } \\
\text { forming a void in } \\
\text { the interfacing }\end{array}$} & Binaries (Solid/ Void) \\
\hline & & Deconstruction and reconstruction (Mikano) \\
\hline & & Sculpture \\
\hline & & Penetration (Void penetrates the mass) \\
\hline & & Breaking-in (Void breaks into the mass) \\
\hline & & Free separation (mass separating from Earth) \\
\hline & & Displacement \\
\hline \multirow{4}{*}{\begin{tabular}{|c|} 
Void \\
characteris \\
tics in \\
digital \\
output
\end{tabular}} & \multirow{4}{*}{$\begin{array}{l}\text { Void as needs } \\
\text { achiever }\end{array}$} & The void as a symbolic and aesthetic need \\
\hline & & The void as structural need \\
\hline & & The void as functional need \\
\hline & & The void as environmental need \\
\hline \multirow{15}{*}{$\begin{array}{c}\text { Features } \\
\text { of digital } \\
\text { spatial } \\
\text { structure }\end{array}$} & \multirow{8}{*}{$\begin{array}{l}\text { Features intended } \\
\text { by the designer }\end{array}$} & Interactions between the structure and nature \\
\hline & & Visual penetration \\
\hline & & Porosity \\
\hline & & Interstitial \\
\hline & & Transparency and permeability \\
\hline & & Structure dynamics \\
\hline & & Structure flexibility \\
\hline & & Dynamic abstraction (non-correlation) \\
\hline & \multirow{7}{*}{$\begin{array}{l}\text { Features intended } \\
\text { by the recipient }\end{array}$} & Interactions between the structure and user \\
\hline & & Absurdity and chaos \\
\hline & & Visual anxiety \\
\hline & & Symbolism and abstraction \\
\hline & & Enjoyment and excitement \\
\hline & & Brilliance, uniqueness and synchronization \\
\hline & & Artistic sculptural properties \\
\hline
\end{tabular}




\subsection{The application on the samples:}

In order to verify the research hypothesis which states "adopting the digital void formation strategy to combine digital formation mechanisms which are used to create a void formation that meets the needs in contemporary architecture interfaces". The application will be performed on architectural samples of a different nature with the aim to find a large area to show the effect of void on the formation of interfaces which will eventually show the characteristics of digital spatial structure. Samples were selected within spatial contexts (global, Arab and local) to clarify the possibility of the impact on them despite the change of times.

\subsubsection{China Central Television Project CCTV}

\begin{tabular}{|c|c|c|}
\hline The & hina Central Televi & \\
\hline & & \\
\hline & & \\
\hline \multicolumn{3}{|c|}{$\overline{\text { Descriptio }}$} \\
\hline \multicolumn{3}{|c|}{$\begin{array}{l}\text { It was designed with } 473 \mathrm{~m}^{2} \text { of floor space. The } \\
\text { China and a potential for digital design, as the ne } \\
\text { aesthetic and symbolic. The conceptual process } \\
\text { dimensional concept of architecture. It was desig } \\
\text { space. The building is a symbol for China and a p } \\
\text { as the need of the void design was aesthetic and } \\
\text { process was based on a three-dimensional conce } \\
\text { order to understand the distortion of its forms, we } \\
\text { dimensions at the same time, that is, to introduce } \\
\text { by using modeling with a computer program, } \\
\text { formation are destroyed, and new digital rules of } \\
\text { bring architecture closer to sculpture. [39] The con } \\
\text { building is a challenge because it is located in a } \\
\text { here was generated by the design to achieve a str } \\
\text { the durability necessary to resist potential seisn } \\
\text { advanced non-linear simulation. [40] A "diagrid" } \\
\text { triangular steel tubes was adopted for the exte } \\
\text { structure that resists gravity and side forces, by a } \\
\text { mechanism on the force paths, so that the int } \\
\text { impressive architectural appearance of the stru } \\
\text { structural, that is, emerging from the structure. } \\
\text { depends on achieving integration in the design }\end{array}$} \\
\hline
\end{tabular}

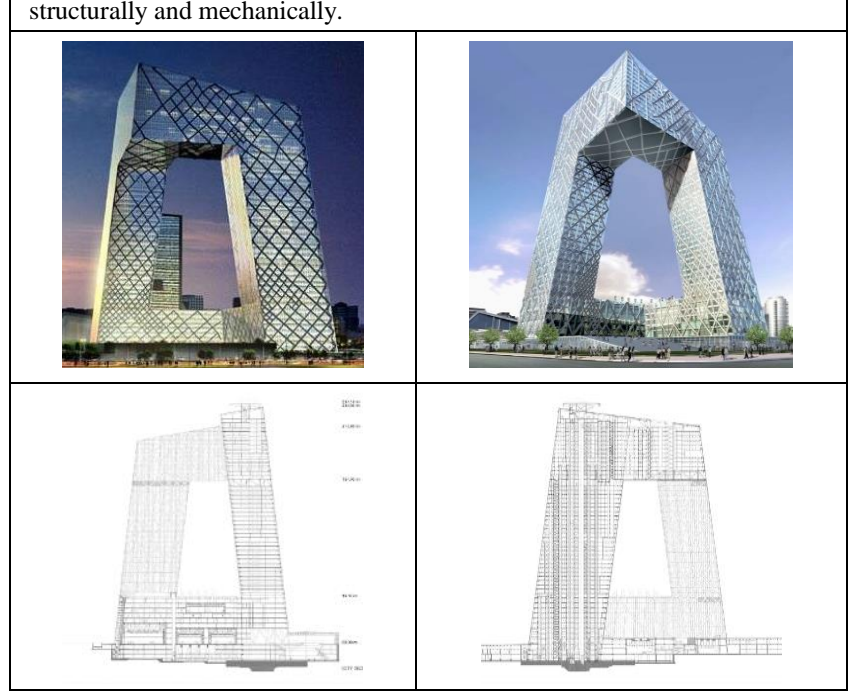

4.1.2. Opus Tower in Dubai

\begin{tabular}{|l|l|c|}
\hline The project & Opus Tower & Sample Code \\
\hline Location & United Arab Emirates 2019 & \multirow{2}{*}{ B } \\
\hline Design & $\begin{array}{l}\text { Zaha Hadid, Patrik } \\
\text { Schumacher and Christos } \\
\text { Passas Omniyat Company }\end{array}$ & \\
\hline \multicolumn{2}{|c|}{ Project Description } \\
\hline
\end{tabular}

The opus building in Dubai is an iconic architecture in the Middle East and the world, designed with a space of $(84345.0 \mathrm{~m} 2)$ with the latest international models to serve as a cityscape of the Middle East, taking the form of the cube. The cube is then 'carved', creating a central void that is an important volume within the building, providing views to the exterior from the center of the building. The free-formed fluidity of this eight-story void contrasts with the precise orthogonal geometry of the surrounding cube.

The building is comprised of two structures that are linked by a height of 21 floors, with a hidden base that makes it appear floating above the surface of the earth, and with a night view different from the day, as it appears during the day as shinning full cube due to the sunlight. At night, the lights fill the voids, as its glass interface absorbs light and shines a wonderful artificial lighting. The design shows the brilliant innovative quality of Zaha Hadid's work, expressing a sense of sculpture that reinvents the balance between solid and void, dark and transparent, inside and outside. So organic void is considered as the focal point of the design, which contrasts beautifully with the surrounding architecture, while presenting unexpected views for outside from the center of the building, giving the building a high aesthetic and interactivity with the outside environment. [40]
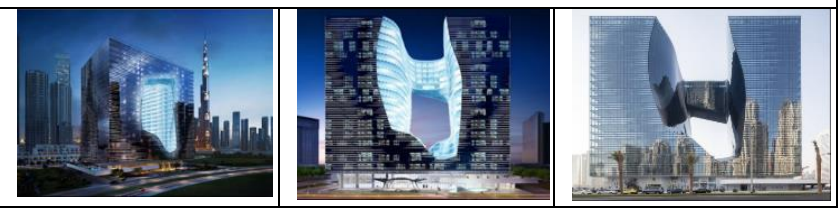

\subsubsection{The Project of Iraqi General Secretariat of the Council of Ministers}

\begin{tabular}{|c|c|c|}
\hline The project & $\begin{array}{c}\text { Iraqi General Secretariat of the } \\
\text { Council of Ministers }\end{array}$ & Sample Code \\
\hline Location & Iraq/ Baghdad / 2010 & \multirow{2}{*}{ c } \\
\hline Design & Manhal Al-Haboobi - CAP Office & \\
\hline \multicolumn{3}{|c|}{ Project Description } \\
\hline
\end{tabular}

A contemporary architectural work which represents the Mesopotamian civilization. The project is unique and special. The building space is $178,000 \mathrm{~m}^{2}$ with a height of 12 floors. The form consists of two main parts: the "seal" building which is topped by a tower, and the "ring building" which forms the base of the building with four main entrances to the project. The building is characterized by achieving sustainability with the latest technologies. Form generation was processed like the biological process in which the organism develops physically after birth or hatching. [41] The formal reference, represented by meanings and symbols, was chosen to discover a specific symbol to the civilization of Iraq, to gain dimensions represented by the infinite motion of the structure of this two-dimensional symbol and transform it into a three-dimensional composition using the method of formal impossibility, in addition to employing contemporary digital technologies in the design, production, and modeling of the project. [42] Making a slight curve in the building implies dynamism, continuity, and an expression of infinity. As for the void formation mechanism, it was applied through the contrast in the relation between (solid / Void). [40]

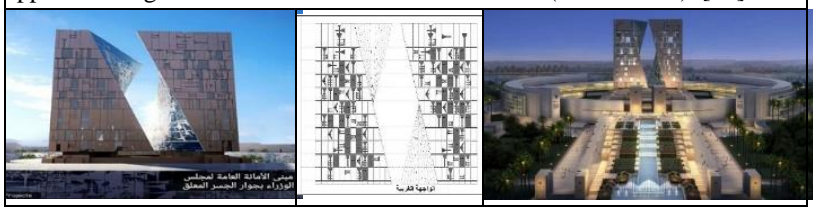


Table 3: Applying the terms on the samples (A, B, C), (Source: Prepared by the two researchers)

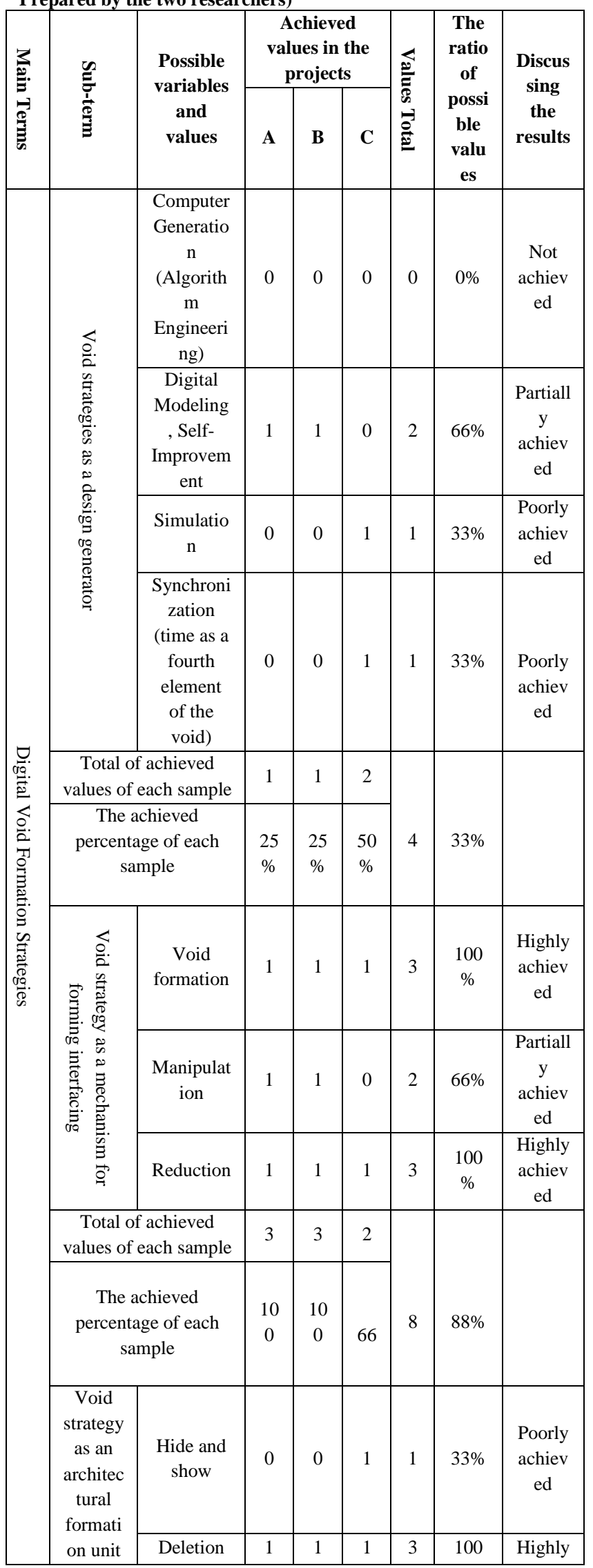

\begin{tabular}{|c|c|c|c|c|c|c|c|c|}
\hline & & $\begin{array}{l}\text { (hiding } \\
\text { some } \\
\text { parts of } \\
\text { the mass) }\end{array}$ & & & & & $\%$ & $\begin{array}{c}\text { achiev } \\
\text { ed }\end{array}$ \\
\hline & $\begin{array}{r}\text { Tot } \\
\text { value }\end{array}$ & $\begin{array}{l}\text { achieved } \\
\text { ach sample }\end{array}$ & 1 & 1 & 2 & & & \\
\hline & $\begin{array}{r}\mathrm{T} \\
\text { perc }\end{array}$ & $\begin{array}{l}\text { hieved } \\
\text { ge of each } \\
\text { nple }\end{array}$ & $\begin{array}{l}50 \\
\%\end{array}$ & $\begin{array}{l}50 \\
\%\end{array}$ & $\begin{array}{l}10 \\
\%\end{array}$ & 4 & $66 \%$ & \\
\hline & & $\begin{array}{c}\text { Binaries } \\
\text { (Solid/ } \\
\text { Void) }\end{array}$ & 1 & 1 & 1 & 3 & $\begin{array}{c}100 \\
\%\end{array}$ & $\begin{array}{c}\text { Highly } \\
\text { achiev } \\
\text { ed }\end{array}$ \\
\hline & 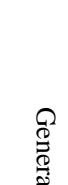 & $\begin{array}{l}\text { Deconstru } \\
\text { ction and } \\
\text { reconstruc } \\
\text { tion } \\
\text { (Mikano) }\end{array}$ & 1 & 1 & 0 & 2 & $66 \%$ & $\begin{array}{c}\text { Partiall } \\
\text { y } \\
\text { achiev } \\
\text { ed }\end{array}$ \\
\hline & 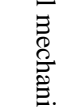 & Sculpture & 1 & 1 & 1 & 3 & $\begin{array}{c}100 \\
\%\end{array}$ & $\begin{array}{c}\text { Highly } \\
\text { achiev } \\
\text { ed }\end{array}$ \\
\hline & $\begin{array}{l}3 \\
0 \\
0 \\
0 \\
0 \\
0 \\
3\end{array}$ & $\begin{array}{l}\text { Penetratio } \\
\mathrm{n} \text { (Void } \\
\text { penetrates } \\
\text { the mass) }\end{array}$ & 0 & 0 & 1 & 1 & $33 \%$ & $\begin{array}{c}\text { Poorly } \\
\text { achiev } \\
\text { ed }\end{array}$ \\
\hline & 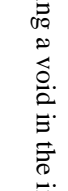 & $\begin{array}{c}\text { Breaking- } \\
\text { in (Void } \\
\text { breaks } \\
\text { into the } \\
\text { mass) }\end{array}$ & 1 & 0 & 0 & 1 & $33 \%$ & $\begin{array}{c}\text { Poorly } \\
\text { achiev } \\
\text { ed }\end{array}$ \\
\hline & 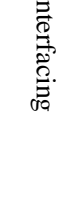 & $\begin{array}{c}\text { Free } \\
\text { separation } \\
\text { (mass } \\
\text { separating } \\
\text { from } \\
\text { Earth) } \\
\end{array}$ & 0 & 0 & 1 & 1 & $33 \%$ & $\begin{array}{c}\text { Poorly } \\
\text { achiev } \\
\text { ed }\end{array}$ \\
\hline & & $\begin{array}{c}\text { Displace } \\
\text { ment }\end{array}$ & 0 & 0 & 1 & 1 & $33 \%$ & $\begin{array}{c}\text { Poorly } \\
\text { achiev } \\
\text { ed }\end{array}$ \\
\hline & $\begin{array}{r}\text { Tot } \\
\text { value }\end{array}$ & $\begin{array}{l}\text { achieved } \\
\text { ach sample }\end{array}$ & 4 & 3 & 5 & & & \\
\hline & $\begin{array}{r}\mathrm{T} \\
\text { perc }\end{array}$ & $\begin{array}{l}\text { hieved } \\
\text { ge of each } \\
\text { nple }\end{array}$ & $\begin{array}{l}57 \\
\%\end{array}$ & $\begin{array}{l}42 \\
\%\end{array}$ & $\begin{array}{l}71 \\
\%\end{array}$ & 2 & $56 \%$ & \\
\hline 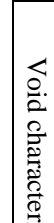 & $\begin{array}{l}\grave{\vdots} \\
\text { ह. } \\
\text { है. }\end{array}$ & $\begin{array}{l}\text { The void } \\
\text { as a } \\
\text { symbolic } \\
\text { and } \\
\text { aesthetic } \\
\text { need }\end{array}$ & 1 & 1 & 1 & 3 & $\begin{array}{c}100 \\
\%\end{array}$ & $\begin{array}{c}\text { Highly } \\
\text { achiev } \\
\text { ed }\end{array}$ \\
\hline 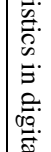 & 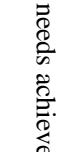 & $\begin{array}{l}\text { The void } \\
\text { as } \\
\text { structural } \\
\text { need }\end{array}$ & 1 & 1 & 0 & 2 & $66 \%$ & $\begin{array}{c}\text { Partiall } \\
\text { y } \\
\text { achiev } \\
\text { ed } \\
\end{array}$ \\
\hline 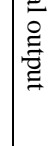 & & $\begin{array}{c}\text { The void } \\
\text { as } \\
\text { functional } \\
\text { need }\end{array}$ & 0 & 1 & 0 & 1 & $33 \%$ & $\begin{array}{c}\text { Poorly } \\
\text { achiev } \\
\text { ed }\end{array}$ \\
\hline
\end{tabular}




\begin{tabular}{|c|c|c|c|c|c|c|c|c|}
\hline & & $\begin{array}{l}\text { The void } \\
\text { as } \\
\text { environm } \\
\text { ental need }\end{array}$ & 0 & 1 & 1 & 2 & $66 \%$ & $\begin{array}{c}\text { Partiall } \\
\text { y } \\
\text { achiev } \\
\text { ed }\end{array}$ \\
\hline & $\begin{array}{r}\text { Tot } \\
\text { value }\end{array}$ & $\begin{array}{l}\text { achieved } \\
\text { ach sample }\end{array}$ & 2 & 4 & 2 & & & \\
\hline & $\begin{array}{r}\mathrm{T} \\
\text { perc }\end{array}$ & $\begin{array}{l}\text { hieved } \\
\text { ge of each } \\
\text { aple }\end{array}$ & $\begin{array}{l}50 \\
\%\end{array}$ & $\begin{array}{c}10 \\
0\end{array}$ & $\begin{array}{l}50 \\
\%\end{array}$ & 8 & $66 \%$ & \\
\hline & & $\begin{array}{l}\text { Interactio } \\
\text { ns } \\
\text { between } \\
\text { the } \\
\text { structure } \\
\text { and nature }\end{array}$ & 0 & 1 & 0 & 1 & $33 \%$ & $\begin{array}{c}\text { Poorly } \\
\text { achiev } \\
\text { ed }\end{array}$ \\
\hline & & $\begin{array}{c}\text { Visual } \\
\text { penetratio } \\
\mathrm{n}\end{array}$ & 1 & 1 & 1 & 2 & $66 \%$ & $\begin{array}{c}\text { Partiall } \\
\text { y } \\
\text { achiev } \\
\text { ed }\end{array}$ \\
\hline & $\begin{array}{l}0_{0}^{7} \\
\stackrel{\Xi}{\Xi}\end{array}$ & Porosity & 0 & 1 & 0 & 1 & $33 \%$ & $\begin{array}{c}\text { Poorly } \\
\text { achiev } \\
\text { ed }\end{array}$ \\
\hline & $\begin{array}{l}8 \\
\stackrel{0}{0} \\
\stackrel{0}{0}\end{array}$ & $\begin{array}{c}\text { Interstitial } \\
\text { ity }\end{array}$ & 1 & 1 & 1 & 3 & $\begin{array}{c}100 \\
\%\end{array}$ & $\begin{array}{l}\text { Highly } \\
\text { achiev } \\
\text { ed }\end{array}$ \\
\hline & $\begin{array}{l}\vec{\sigma} \\
\vec{c} \\
\vec{\sigma} \\
\overrightarrow{0} \\
\frac{0}{0} \\
\frac{0}{0.0}\end{array}$ & $\begin{array}{c}\text { Transpare } \\
\text { ncy and } \\
\text { permeabil } \\
\text { ity }\end{array}$ & 1 & 1 & 1 & 3 & $\begin{array}{c}100 \\
\%\end{array}$ & $\begin{array}{l}\text { Highly } \\
\text { achiev } \\
\text { ed }\end{array}$ \\
\hline$\overbrace{\overparen{8}}^{\pi}$ & $\Xi$ & $\begin{array}{l}\text { Structure } \\
\text { dynamics }\end{array}$ & 1 & 1 & 0 & 2 & $66 \%$ & $\begin{array}{c}\text { Partiall } \\
\text { y } \\
\text { achiev } \\
\text { ed }\end{array}$ \\
\hline$\stackrel{\rho}{2}$ & & $\begin{array}{l}\text { Structure } \\
\text { flexibility }\end{array}$ & 0 & 0 & 0 & 0 & $0 \%$ & $\begin{array}{c}\text { Not } \\
\text { achiev } \\
\text { ed }\end{array}$ \\
\hline 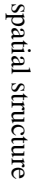 & & $\begin{array}{c}\text { Dynamic } \\
\text { abstractio } \\
\text { n (non- } \\
\text { correlatio } \\
\text { n) }\end{array}$ & 1 & 1 & 1 & 3 & $\begin{array}{c}100 \\
\%\end{array}$ & $\begin{array}{l}\text { Highly } \\
\text { achiev } \\
\text { ed }\end{array}$ \\
\hline & $\begin{array}{r}\text { Tot } \\
\text { value }\end{array}$ & $\begin{array}{l}\text { achieved } \\
\text { ach sample }\end{array}$ & 5 & 7 & 4 & & & \\
\hline & $\begin{array}{r}\mathrm{T} \\
\text { perc }\end{array}$ & $\begin{array}{l}\text { hieved } \\
\text { ge of each } \\
\text { aple }\end{array}$ & $\begin{array}{l}62 \\
\%\end{array}$ & $\begin{array}{l}87 \\
\%\end{array}$ & $\begin{array}{l}50 \\
\%\end{array}$ & $\begin{array}{l}1 \\
5\end{array}$ & $62 \%$ & \\
\hline & 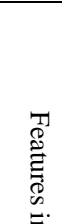 & $\begin{array}{l}\text { Interactio } \\
\text { ns } \\
\text { between } \\
\text { the } \\
\text { structure } \\
\text { and user }\end{array}$ & 1 & 0 & 0 & 1 & $33 \%$ & $\begin{array}{c}\text { Poorly } \\
\text { achiev } \\
\text { ed }\end{array}$ \\
\hline & 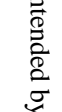 & $\begin{array}{l}\text { Absurdity } \\
\text { and chaos }\end{array}$ & 0 & 1 & 0 & 1 & $33 \%$ & $\begin{array}{c}\text { Poorly } \\
\text { achiev } \\
\text { ed }\end{array}$ \\
\hline & 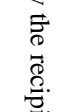 & $\begin{array}{l}\text { Visual } \\
\text { anxiety }\end{array}$ & 0 & 1 & 0 & 1 & $33 \%$ & $\begin{array}{c}\text { Poorly } \\
\text { achiev } \\
\text { ed }\end{array}$ \\
\hline & $\stackrel{\vec{g}}{=}$ & $\begin{array}{c}\text { Symbolis } \\
\text { m and } \\
\text { abstractio } \\
n\end{array}$ & 1 & 1 & 0 & 2 & $66 \%$ & $\begin{array}{l}\text { Partiall } \\
\text { y } \\
\text { achiev } \\
\text { ed }\end{array}$ \\
\hline
\end{tabular}

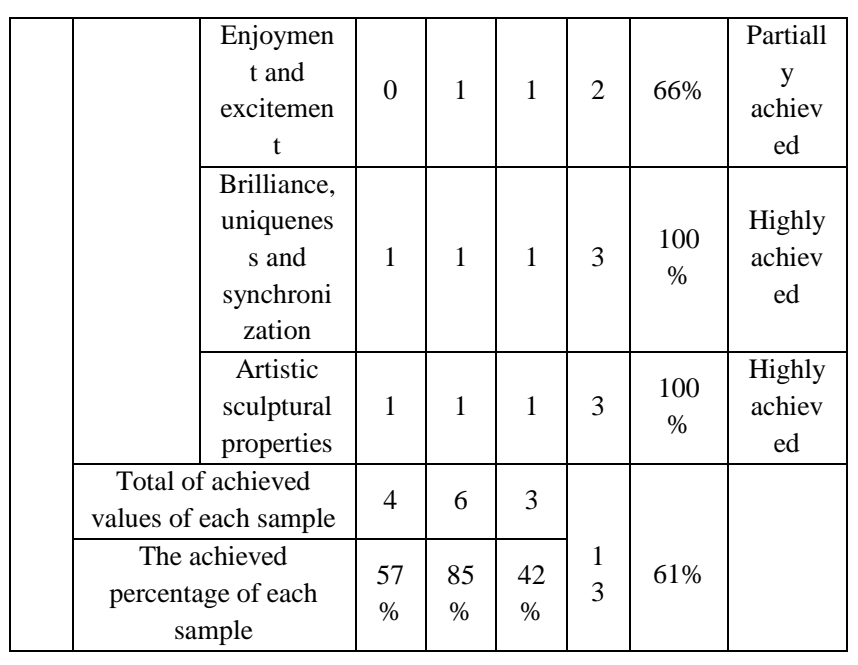

\subsection{Analyzing and discussing the results:}

The paragraph explains the most important results of the application on the selected samples:

\subsubsection{The results related to the term of digital void formation strategies:}

The results of void formation strategies in digital architecture interfaces revealed that (void strategy as a mechanism for forming interfaces) achieved the highest percentage within the four main strategies by $(88 \%)$ compared to the lowest percentage of (void strategy as a design generator) which is $(33 \%)$. While the strategy of (void strategy as an architectural formation unit) achieved (66\%), followed by (the general mechanisms for forming interfaces in digital architecture) by (56\%), as shown in the chart (1-2).

First: Void strategy as a mechanism for forming interfaces: Which is classified into three main mechanisms (void formation, reduction, and manipulation). Both of (void mechanism) and (reduction mechanism) achieved the highest percentage of (100\%), while (manipulation mechanism) achieved (66). As for the single results of each project, we notice a difference in the achieved results, as results showed similar percentages in the results of the selected samples (A, B) by achieving a percentage of $(100 \%)$, followed by the sample (C) with a percentage of (66) \%). Therefore, we conclude that the samples (A, B) are the most creative as they included the use of the three mechanisms (void formation, reduction, and manipulation) to achieve a unique and creative spatial structure.

Second: Void strategy as an architectural formation unit: it is classified into two main mechanisms (hide, show, and deletion). As the term (deletion) achieved the highest percentage of (100\%) compared to (33\%) of (hide and show). As for the single results of each project, we notice similar results for the selected samples (A, B) by achieving a percentage of (50) \%), compared to (100\%) for the sample (C). Therefore, it is clear that the sample (C) relied on the void strategy as a first-order architectural formation unit.

Third: General mechanisms for forming a void in the interfaces: they are classified into several main mechanisms of binaries (solid/void), deconstruction and reconstruction (Mikano), sculpture and penetration (void penetrates the mass), breaking-in (void breaks into mass), free separation (mass separating from Earth) and displacement. 
The binaries (solid/void) and sculpture achieved the highest percentage (100\%), while deconstruction and reconstruction (Mikano) achieved a percentage of $(66 \%)$. Whereas penetration (void penetrates the mass), breaking-in (void breaks into mass), free separation (mass separating from Earth), and displacement achieved (33\%) for each. As for the single results of each project, we notice a difference in the achieved results, as the results showed that the highest percentage of $(71 \%)$ of the sample (C) was achieved, followed by sample (A) with a percentage of $57 \%$, while sample (B) achieved (42) \%).

Fourth: The void strategy as a generator for the general design: it is classified into several sub-terms which are computer generation (algorithm engineering), digital modeling (self-improvement), simulation, and synchronization. The results showed that digital modeling (self-improvement) achieved the highest percentage of (66\%), compared to $(0 \%)$ for (computer generation). While (simulation and synchronization) achieved a percentage of (33\%) for each. As for the single results of each project, we notice a difference in the achieved results, as the results showed that the highest percentage of $(50 \%)$ was achieved for sample (C), followed by samples (A, B) with a percentage of $(25 \%)$.

\subsubsection{The results related to the term of void characteristics in the digital output:}

The feature of void as a needs achiever in the interfaces of digital architecture revealed the superiority of (void as a symbolic and aesthetic need) by achieving the highest percentage (100\%) compared to the lowest percentage of (void as a functional need) which is (33\%), while both of (void as structural need) and (void as environmental need) achieved (66\%) for each, as shown in the chart (1-3). As for the single result of each project, we notice a difference in the achieved results. As the results showed that the highest percentage (100\%) of the sample (B) was achieved, while the samples (A, C) achieved a percentage of (50\%) for each, which indicates that sample (B) formed the void in the interface to achieve the functional, aesthetic, structural and environmental needs.

\subsubsection{The results related to the term of features of digital spatial structure:}

the results showed the superiority of (interstitially, transparency, permeability, dynamic abstraction, brilliance, uniqueness and sculptural properties) by achieving the highest percentage (100\%) compared to (0\%) for the term (structure flexibility), while (visual penetration, structure dynamics, symbolism, abstraction and enjoyment and excitement) achieved a percentage of $(66 \%)$ for each. The values of each of (the interaction between structure and nature, porosity, and the interaction between structure and the user, absurdity, chaos, and visual anxiety) were similar in achieving (33\%) for each. As for the single result of each project, we notice a difference in the achieved results, as the results showed that the highest percentage (85\%) of the sample (B) was achieved, while the sample (A) achieved a percentage of $(57 \%)$, followed by the sample (C) with (42\%). This indicates that the sample (B) was distinguished by achieving most of the features that the void gives to the output, such as the interaction between the structure and nature, visual penetration, porosity, interstitiality, transparency, permeability, and structure dynamics in addition to brilliance, uniqueness, synchronization and other sculptural and artistic properties.

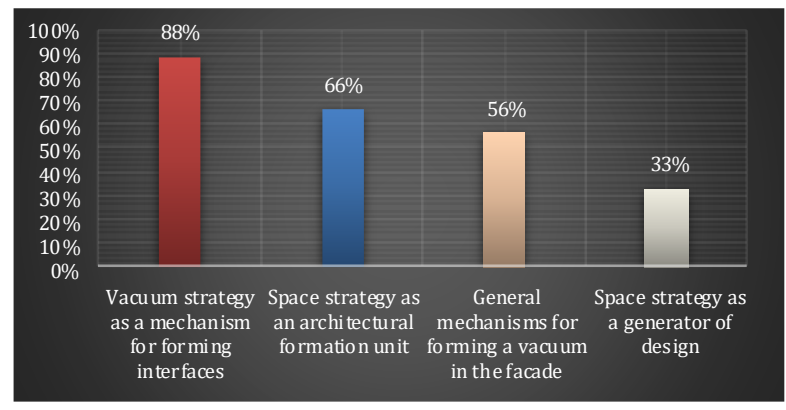

Scheme 2: ratios achieved strategies void forming digital (Prepared by the researchers)

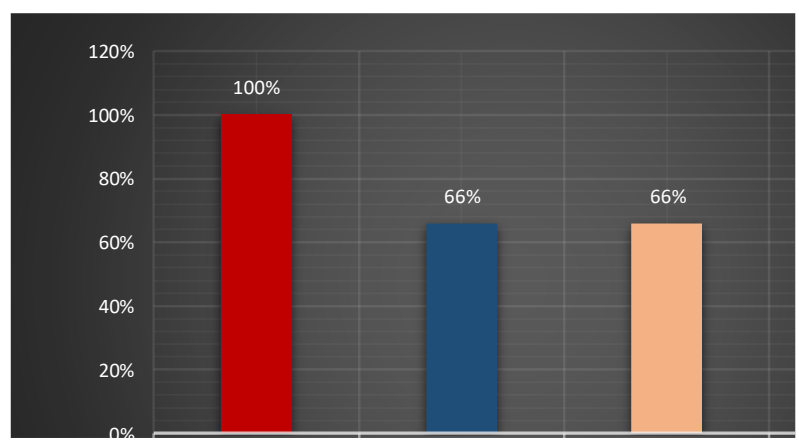

Scheme 3: ratios achieved strategies of the void property as a needs investigator (Prepared by the researchers)

\section{Conclusions:}

\subsection{Theoretical part conclusions:}

- The idea of the emergence of an architectural void within the formation of the mass started in the outputs of the modern architecture, as it began to reduce the elements and generate unexplained voids as a result of reduction and simplicity only. As for the deconstruction architecture, the emergence of an architectural void was a clear and distinctive through the adoption of the deconstruction and the non-correlation that led to the formation of voids which directly affected the body of the building.

- The disappearance of boundaries between the exterior and interior over time led to the use of void in the formation of the building's outer mass (at the three-dimensional level), and sometimes the formation of the mass is based on that void which is called (designgenerating void) and the name of the structure which is created by void is (spatial structure) as its formation depended on "geometry" and its methods of formation.

- The perception of the void concept has changed by acquiring new properties such as flexibility and dynamism due to the technologies provided by digitization, as void is connected to time by integrating the inside and outside and adding time as a fourth dimension of architectural output.

- It is necessary to rely on the capabilities provided by technology as a basic form generator to look for strength and durability in order to create void configurations that are consistent with the era of the digital revolution and characterized by dynamism, abstraction and high symbolism. 
- The various forms of the three-dimensional void served as a regulator of formal interrelations in the design process, i.e. to connect and organize the relation between voids and form elements. Therefore, this process is affected by the nature of the geometrical form of the void, and each form has properties distinguishing it and controlling the relation between the elements, so the form of the void affects the interrelation between void and other design elements.

- Formulas of creating the architectural void included several forms through the relation between the binaries (solid-void), (absentpresent), (positive-negative) and (hide-show), as the void appears as a spatial output after withdrawal or removal or the deletion of the solid mass, or a vacant space for form, or absence of the form, or it appears as a spatial interference in the variants, such as the convergence zone between two forms, so it is defined as convergence or collision between two forms, where a void or middle space is created by the overlapping of two solid elements.

\subsection{The practical part conclusions}

- The strategies for void creation differentiate in the interfaces of digital architecture according to the idea of the project or the purpose of finding the void for in the interface. To achieve this, architects tend to integrate more than one strategy to reach a distinctive void formation that reflects the high sensory and visual effects and achieves the formal and functional needs for which it was designed. The results showed a primary focus on the void strategy as a mechanism for forming interfaces of digital architecture for the purpose of adding unique aesthetic features and improving the formative properties of the digital void according to the requirements of each project.

- $\quad$ The void is formed to achieve several needs such as (symbolic and aesthetic need, structural need, functional need, and environmental need). The application result showed more than one need was achieved in the same project, since all projects achieved the symbolic and aesthetic need to give symbolism and multiplicity of meaning to the outputs of contemporary architecture and make the output as an attracting force to building and a framework for the urban scene which follows, in addition to other needs.

- $\quad$ The void achieves the structural need in the architectural models by reducing the building weight and achieving balance and stability, and generating economical and highly efficient outputs.

- The formation of void in the interfaces of digital architecture enrich it with features such as the interaction between the structure and nature, visual penetration, porosity, interstitiality, transparency, permeability and structure dynamics in addition to the brilliance, uniqueness, synchronization and other sculptural and artistic properties.

\section{REFERENCES}

[1] Webster, Ninth "New Collegiate Dictionary", G and C Merriam,co. printing,1st printing, USA, 1973.

[2] Al-Fayoumi, Ahmad Muhammad Ali, "The Bright Light", Dar AlMaarif, Cairo, 1977.

[3] Shultz C . Norberg "Existance, Space and Architecture”

[4] Ching, Francis D.K. "Architecture Form ,Space, and Order" 2nd edition, New York ,1996.
[5] Lawson, Bryan "The Language of Space" Routledge, 2001.

[6] Frederick, Matthew, "101 things I learned in architecture school", The MIT Press Cambridge, Massachusetts London, 2007.

[7] Tülay, Şamlığlu \& Kuloğlu, Nilgün , ““CCONCEPTS” IN THE PROCESS OF DESIGNING THE VOID IN THE FORM" Karadeniz Technical University, Department of Architecture,2016.

[8] Al-Dahwi, Soha Hassan: "Transparency as a feature of contemporary architectural productions," research publication, Journal of Engineering and Technology, University of Technology, Baghdad, 2013.

[9] Tamim, Abd al-Rahman Othman, "Sustainable Towers and Integrated Sustainable Architectural Formation", Sudan University of Science and Technology, 2017.

[10] Abdul Jalil, Wijdan Zia, "The Generation of Form and its Relation to Structure in Digital Architecture," published research, Journal of Babylon University, Pure and Applied Sciences and Engineering Sciences, Volume 26, No. 2, 2018.

[11] Leach, N., "Swarm tectonic" In: Leach, N.; Turnbull, D \& Williams C., Editor. Digital Tectonics, John Wiley \& Sons, London,2004.

[12] Al-Haddad, Enas, "The Impact of Contemporary Computer Technologies on Architecture", Master Thesis, University of Technology, Department of Architecture, 2007.

[13] Al-Anbuge, Jinan Hassan Mazloum, "The Space between Architecture in Architecture," Master Thesis, University of Technology, Department of Architecture, 2013.

[14] Al-Kanawati, in particular, "The Role of Void in Architectural Formation and its Importance," Master Thesis in Architectural Engineering, Damascus University, Syria, 2014.

[15] Al-Badri, Hind, "Abstract vacuum configurations as a creative theory and their aesthetic role in developing contemporary ceramic concepts", Second International Conference, Sustainable Development of Societies in the Arab World, 2015.

[16] Prestige, Khaled Mahmoud, "Contemporary Architecture and Technology: A Critical View of the Impact of Digital Technology on the Prevailing Architectural Trends with the Beginning of the Twenty-first Century", published research, Umm Al-Qura University, No. 1, 2013.

[17] Graham Collier : Form Space and Vision, Abbeville press, New York , 1963.

[18] Mahjoub, Yasser Othman, "Introduction to Architectural Design," 2012.

[19] Abd Al-Baqi, Abd Al-Baqi Jbara, "Interrelationships between the structural and architectural form in free curved formations," Master Thesis, Sudan University of Science and Technology, Department of Architecture, 2018.

[20] Minerva, Fadel, "The Impact of Philosophical Theses on Shaping the Architectural Void", MA Thesis, University of Aleppo, Department of Architecture, 2014.

[21] Charleson ,Andrew, "Structure As Architecture",Architectural Press2005.

[22] Masouh, Emad Abdou, "The Architectural Void and Its Reflection on the Advancement of Design Idea," published research, Al-Baath University Journal, Volume 37, No. 1, 2015.

[23] Ding-Yu Chung, "The Space Structure, Force Fields, and Dark Matter" Article in Journal of Modern Physics, January 2013.

[24] GAO, WAN-PING , Graduate Institute of architecture, National Chiao-Tung University, 1001 Ta Hsueh Road, Hsinchu, Taiwan

, 2003.

[25] Sana, Murrani," Re-thinking Architectural Form:The Emergence of Self-organized Architectural Form" , Planetary Collegium; Plymouth, $\mathrm{UK}, 2005$.

[26] Khalil, Wael Salah El-Din Bahloul, "The Impact of the Digital Revolution on the Field of Job and Architectural Formation", published research, Misr University for Science and Technology, Faculty of Engineering, Department of Architecture, 2012. 
[27] Salem, N., Digital Architecture Theoretical Study Of Digital Design Modelling Master Thesis, Alexandria University, Egypt, 2011.

[28] Schodek ,D. \& Bechthold, M. \& Griggs, K. \& Kao, K. \& Martin, B. and Steinberg M. , "Digital Design And Manufacturing G: CAD/CAM Applications In Architecture And Design”, 1st Edition, USA, 2005.

[29] Oxman, Rivka, "Theory and Design in the First Digital Age", In: Design Studies 27 229-265, Great Britain, 2006.

[30] Wong, Wusius, "Principles of Form and Design, Two Dimensional Design", John Wiley \& Sons, Inc., Published simultaneously in Canada1993.

[31] Abu Zaarour, Rawand Hamadallah, "The effect of interior design on the success of the content of internal and external architectural spaces", MA thesis, An-Najah National University, College of Graduate Studies, Department of Architecture, Nablus, Palestine, 2013.

[32] Muhammad, Omar, "The stereotactic model between plastic fluency and unconventional materials," published research, Research Portal, 2013.

[33] Farhat, Asaad Saeed: "The philosophical and aesthetic dimensions of the formulation of space works in modern sculpture and their use in teaching stereoscopic formation", , Helwan University, 2004.

[34] Majeed, Rasha Subhi and Mahmoud, Aseel Ibrahim, "Sculpture and Contemporary Architecture" Joint Research, Department of Architecture, University of Technology, Iraqi Journal of Architecture and Planning Engineering, Volume 6, 2010.

[35] Majed, Raed Hameed, "Dazzling Structural Structures in Contemporary Architecture," Master Thesis, University of Technology, Department of Architecture, 2018.

[36] Luisa ,Bravo "City Space Architecture” Bologna, Italy,2013.

[37] Ramadan, Maha El-Sayed Mohamed, "The functional and aesthetic values of architectural openings and their role in enriching the interior void", Architecture and Art Magazine, tenth issue, second part, 2018.

[38] Mohamed, Mohamed Attia Attia, and others, "The effect of the development of construction materials and systems on the evolution of the formulation of the architectural space formation system", published research, Al-Azhar University Journal, Issue 38, January 2016.

[39] Al-Ahbabi, Shaima Hamid \& Al-Okaili, Maha Amer, "Urban Vertical Design", Al-Nahrain University, Babel Magazine, Issue 3, Volume 21, 2013.

[40] https://www.archdaily.com/.

[41] Al-Musawi, Hashem Aboud, "Designing the General Secretariat building for the Council of Ministers in a local color," article published by Al-Noor Center on the Internet, 2012.

[42] Al-Morshedy, Siraj Jabbar Kazim, "The Impact of Digital Technology on the Contemporary Architectural Form," Master Thesis, University of Technology, Department of Architecture, 2017. 